\title{
Experimental validation of numerical modelling of the bridge-track-moving train system
}

\author{
P. Szurgott ${ }^{1}$, M. Klasztorny ${ }^{1}$, J. Grosel ${ }^{2}$ \& Z. Wojcicki ${ }^{2}$ \\ ${ }^{1}$ Department of Mechanics and Applied Computer Science, \\ Military University of Technology, Poland \\ ${ }^{2}$ Institute of Civil Engineering, Wroclaw University of Technology, \\ Poland
}

\begin{abstract}
A new methodology of physical and FE modelling and simulation of bridge-track -moving train (BTT) systems has been developed with the use of commercial CAE systems. A methodology is related to composite (steel-concrete) bridges, ballasted tracks and high-speed trains. In the methodology, Altair HyperMesh, LS-DYNA, LS-PrePost and HyperView software was applied. The methodology is based on homogenization of reinforced concrete (RC) platform slab, RAIL_TRACK and RAIL_TRAIN LS-Dyna's modules for simulating the moving train-track interaction, non-linear modelling of rail fastenings and crushed stone ballast, application of cylindrical and revolute constrained joints and discrete springs and dampers for modelling suspensions in rail-vehicles. For experimental validation of numerical modelling and simulation of BTT systems, the KNI 140070 composite viaduct and the EuroCity EC 114 train moving at $160 \mathrm{~km} / \mathrm{h}$ have been selected. The experimental setup contained Keyence LK-G 157 system (CCD laser displacement sensors), PULSE system (acceleration sensors), and PHANTOM v12 high-speed camera. According to the experiment plan, selected vertical displacements and vertical and horizontal accelerations vs. time were measured. The simulated time-histories of displacements and accelerations have been compared to respective experimental diagrams. The results have proved that the validation is positive.
\end{abstract}

Keywords: railway bridge, ballasted track, high-speed train, numerical modelling, simulation, experimental tests, validation. 


\section{Introduction}

Nowadays, serious problems with durability protection of bridge superstructures, tracks and approach zones loaded by high-speed trains are observed. First of all, it results from complexity of bridge-track-moving train (BTT) systems, for which nonlinear models are described by a huge number of parameters. Many of these parameters, describing fasteners, ballast, subsoil layers, rail-vehicles' suspensions, track irregularities, settlements etc., are only estimated and difficult for identification. Producers and research institutions involved in modern high-speed trains do not bring to light structural details, values of parameters or their research results. These circumstances make exact prediction of dynamic response of bridges to moving trains very difficult.

In the 2 nd half of the 20th century scientists mostly developed analyticnumerical methods in dynamics of railway bridges, summarized in monographs (Klasztorny $[1,2]$ ). Simple problem-oriented computer codes were created and used for simulations. At present, one may observe various numerical approaches to dynamics of railway bridges but commercial CAE systems based on FEM are, in general, not used in this field by Klasztorny [2], Yang et al. [3], Cheng et al. [4], Au et al. [5], Zhang et al. [6], Song and Choi [7]. Summing up, assuming vibrations of BTT systems may be considered as 3D but symmetric with respect to the vertical longitudinal plane of symmetry. Applications of advanced CAE systems in dynamics of bridges are at early stage of its development.

\section{Description of the KNI 140070 composite viaduct, the ballasted track and the EC 114 PRAHA train}

The composite (steel-concrete) viaduct No. KNI 140070, located at $200.794 \mathrm{~km}$ on the Polish Central Main (PCM) Line No. 4-E 65, has been selected for numerical modelling, simulation and validation [8]. There is considered the bridge span under track No. 1 (fig. 1).

After recent modernization, the viaduct has the $k=+2$ rail-line classification coefficient. A track spacing equals $4.57 \mathrm{~m}$, the spans are of $14.40 \mathrm{~m}$ theoretical length and $15.34 \mathrm{~m}$ total length. Four main beams are $0.77 \mathrm{~m}$ high and made of

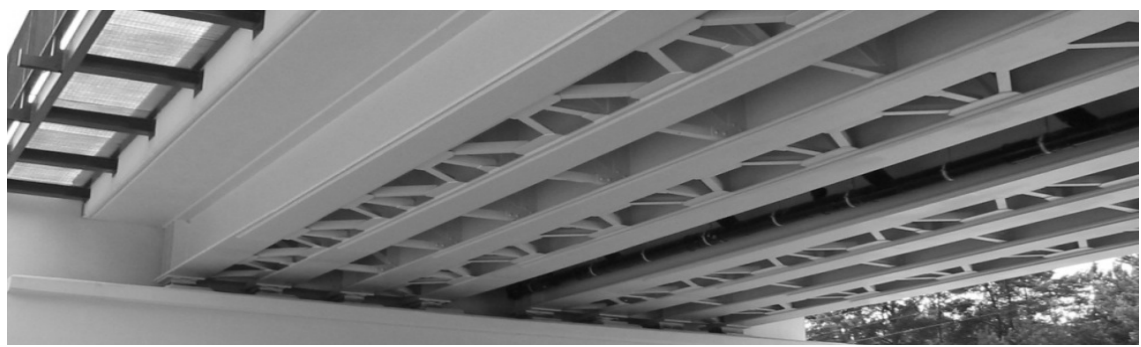

Figure 1: The modernized viaduct No. KNI 140070 composed of two separate spans, located at $200.794 \mathrm{~km}$ on the PCM Line, Poland: bottom view on the main beams and bracing. 
St3M steel. Bottom flanges have been enforced with additional cover plates. The thickness of a new RC platform ranges from $0.29 \mathrm{~m}$ in the track axis to $0.25 \mathrm{~m}$ at the side wall. The platform is made of C35 concrete reinforced with AII/18G2-b steel rebars. The side wall is made of $\mathrm{C} 30$ concrete and has vertical dilatations at $1 / 4,1 / 2$, and $3 / 4$ of the span length. The RESTON rolling bearings (on the left support) can shift up to $\pm 50 \mathrm{~mm}$ in the longitudinal direction. Bearings under the left inside main beam are unmovable in the lateral direction; the remaining bearings can displace in the lateral direction up to $\pm 20 \mathrm{~mm}$.

A scheme of the longitudinal section of the KNI 140070 viaduct is depicted in fig. 2 where all elements taken in the FE modelling are marked, i.e. the homogenized platform (the slab and the walls), the main beams set, the vertical ribs welded to webs of the main beams, the horizontal bearing plates welded to the bottom flanges of the main beams (over the bearings).
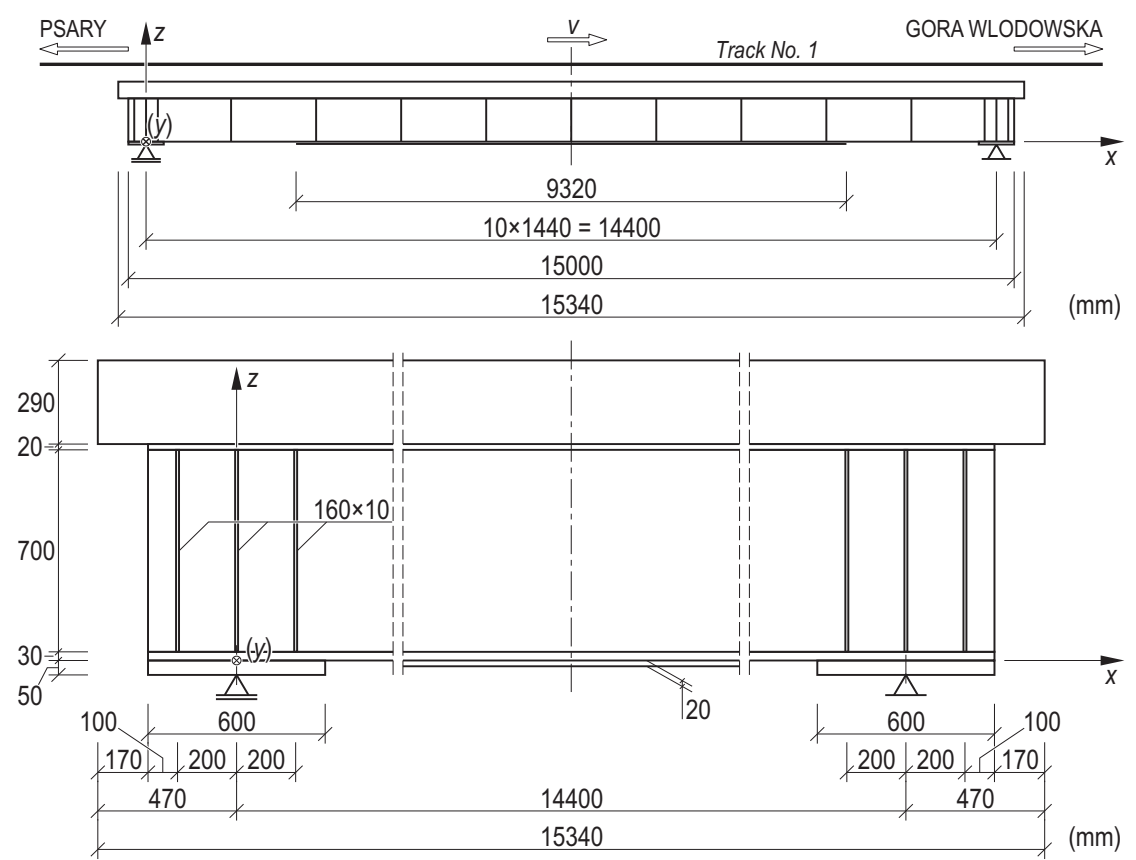

Figure 2: $\quad$ The longitudinal section of the KNI 140070 viaduct in the $x z$ plane.

The track structure before modernization consists of UIC 60 rails, PS-94/SB/ /UIC-60 sleepers with SB3 fasteners, and crushed stone ballast of the first class. The ballast layer is $0.35 \mathrm{~m}$ thick under sleepers. The embankment in the approach zones contains cement-stabilized subsoil while outside the approach zones a $0.2 \mathrm{~m}$ thick sand-gravel mix top layer has been applied. The tracks over the viaduct are quasi-rectilinear; there exists a horizontal arc of $R=4000 \mathrm{~m}$ radius. Schemes of the longitudinal and cross sections of the ballasted track in the viaduct area are shown in fig. 3. 

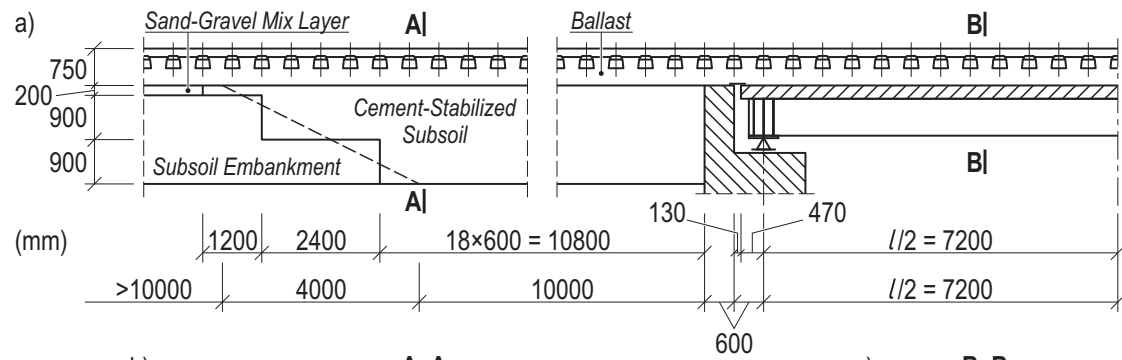

b)

$\underline{A-A}$

c) $\underline{B-B}$
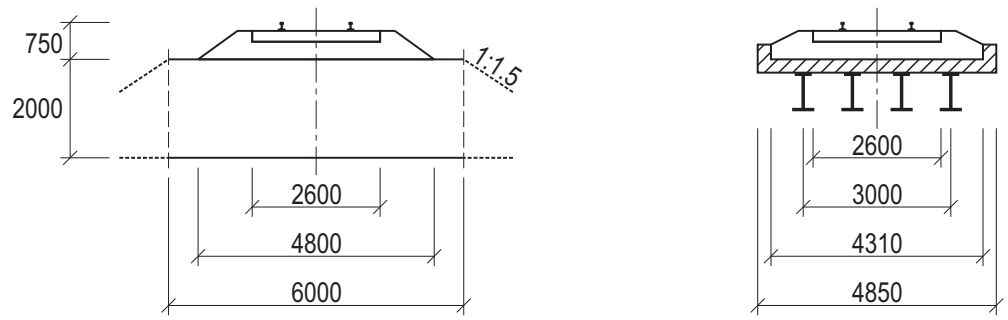

Figure 3: The ballasted track in the KNI 140070 bridge zone: the longitudinal section (a); the cross-section in the approach zone (b); the crosssection over the bridge span (c).

The EC 114 PRAHA EuroCity train, moving at $160 \mathrm{~km} / \mathrm{h}$ over the bridge, has been taken into consideration. The trainset consists of 6 units. Car lengths, centre pins' distances and wheel sets' distances are reflected in fig. 4. All units are equipped with two independent two-axle bogies.

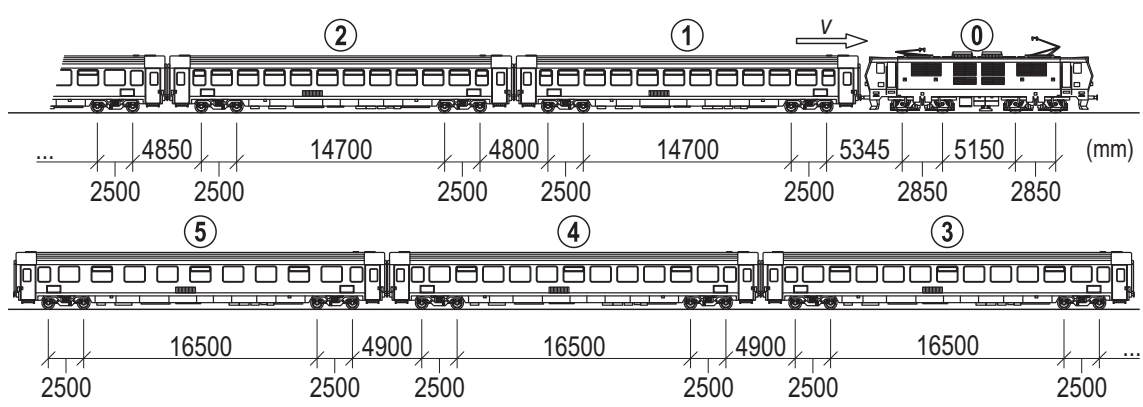

Figure 4: $\quad$ A scheme of EC 114 PRAHA Euro City trainset.

\section{Physical and numerical modelling of the BTT system}

The following concept has been developed in physic modelling of the viaduct. Since the reinforcement of the RC platform is distributed quasi-uniformly in the specified platform sectors, the slab and the wall of the platform can be homogenized. After homogenization the slab and the wall are reflected by linear 
viscoelastic orthotropic materials described by 3 Young's moduli, 3 Poisson's ratios, and 3 shear moduli in each subarea. A cross-section of the platform slab is approximated by a rectangle of $0.27 \mathrm{~m}$ height. The platform is symmetrised via replacing a single dilated wall with two smaller dilated walls on both sides of the platform slab. The original and approximate structures have the same values of mass and cross-section area. The material of steel main beams is linearly viscoelastic and isotropic. The vertical and horizontal bracing in the main beams' set is neglected. All bearings on the abutments are assumed to be unmovable in the lateral direction. The temperature changes are not taken into consideration.

Figure 5 depicts the original (dashed lines) and symmetrised (continuous lines) cross-sections, the longitudinal section of the viaduct and the symmetrised reinforcement close to the original one. Four homogenised subareas in the crosssection have been distinguished.
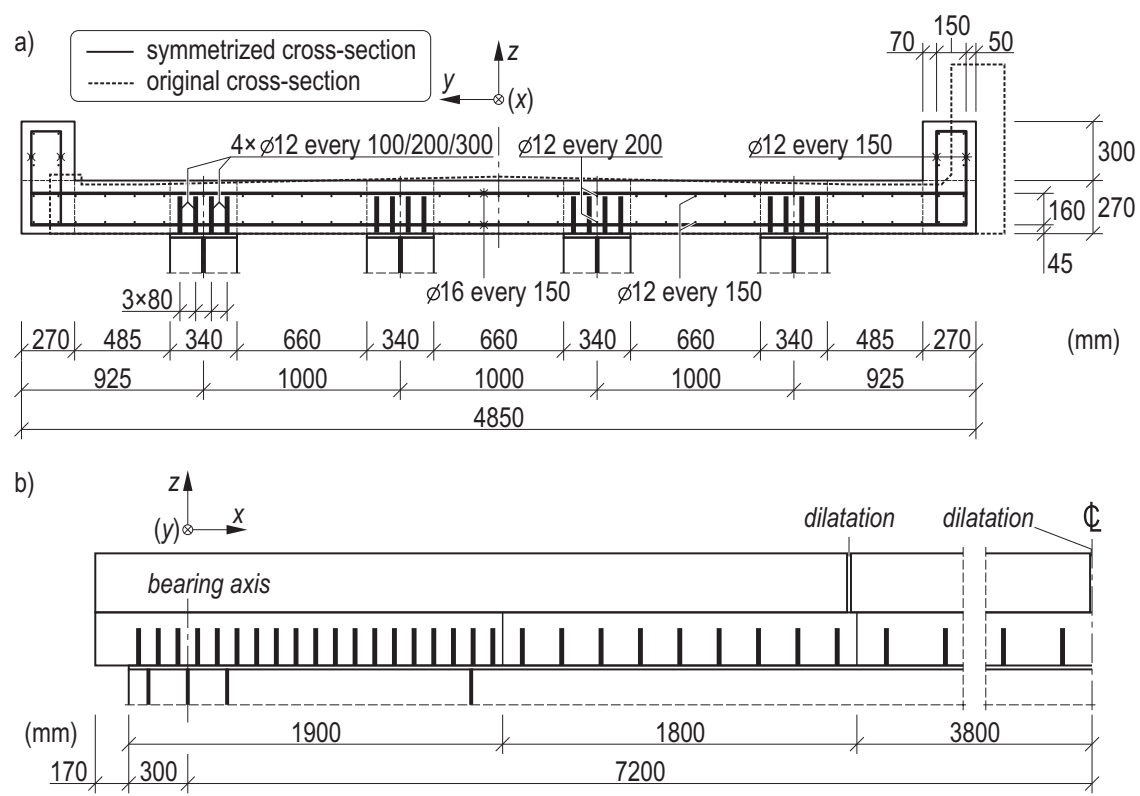

Figure 5: The original and symmetrised cross-sections (a), and the longitudinal section (b) of the KNI 140070 viaduct and the symmetrised reinforcement.

The FE model of the bridge superstructure has been created in Altair HyperMesh software (fig. 6). The numerical model of the bridge superstructure consists of 38964 -node shell elements (steel main beams) and 5568 8-node 48 DOF solid elements (the homogenized RC platform divided into orthotropic parts). Cover plates of the beam bottom flanges are modelled as an additional layer of finite shell elements. Roller bearings on the left bridge abutment and pivot bearings on the right bridge abutment have been reflected by respective constraints. 


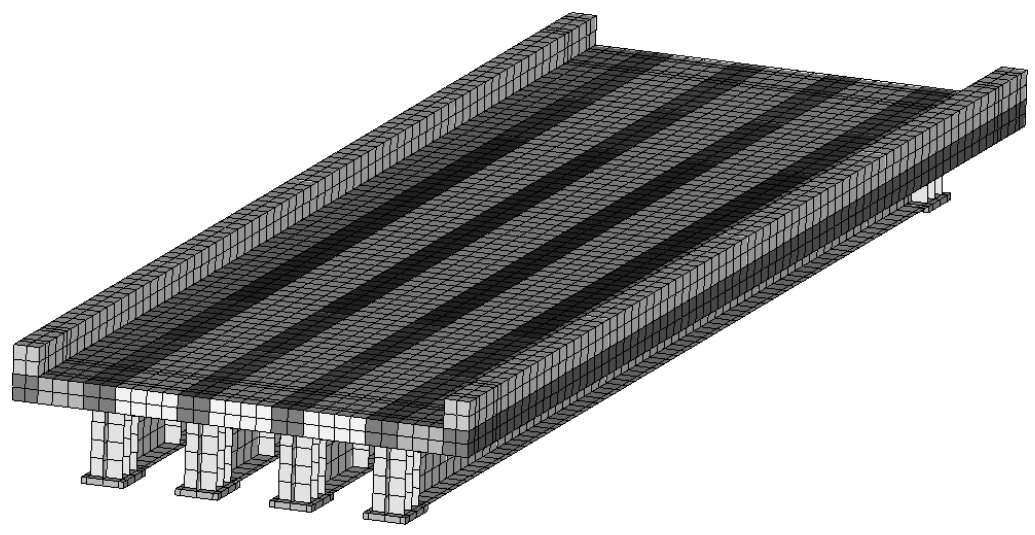

Figure 6: $\quad$ The FE model of the KNI 140070 viaduct superstructure.

The following assumptions have been made in physic modelling of the track. The rail-line axis is rectilinear, and — in the unloading state - the rails are rectilinear. No rail surface irregularities appear. Vibrations of the track are small and symmetric with respect to the vertical $x z$ plane. The rails are prismatic beams deformable in flexure and shear, made of linearly viscoelastic material. Layers of the embankment are considered as a linearly viscoelastic material continuum.

Rail fasteners were simulated using massless one-dimensional discrete nonlinear spring and damper elements oriented vertically. The embankment has been reflected approximately by a rectangular prism with unmovable side and bottom boundary surfaces and meshed using 8-node 24 DOF solid elements. Sleepers are modelled as rigid beams vibrating only vertically, using finite beam elements and respective constraints. The ballast layer has been divided into cubicoid columns in coincidence with FE mesh of the parts under the ballast ( 9 ballast columns under each sleeper). Each ballast column was reflected by a vertical set of nonlinear spring and damper elements. The lumped mass distribution for the ballast has been put into the bottom set of the nodal points contacting the platform slab and the top subsoil layers.

Values of geometrical and mechanical parameters of the ballasted track parts are extracted from Klasztorny [1, 2], Niemierko et al. [11], and refs. [10, 12, 13].

RAIL_TRACK and RAIL_TRAIN modules available in LS-DYNA [15] were applied for approximate modelling the train-track interaction (without simulation of wheels' rotation). The wheel-rail contact stiffness amounts to $2 \mathrm{MN} / \mathrm{mm}$ as suggested in ref. [15]. Hughes-Liu beam elements (2-node elements with 12 DOFs [15]) were used for FE modelling of rails bent in the vertical planes. In order to declare a set of integration points for the rail cross-section, the INTEGRATION card has been applied. For each rail a substitute double-tee asymmetric cross-section was assumed, denoted in ref. [15] as Type 10: I-Shape 1. The actual values of the centre-of-gravity location, the area and the geometrical moment of inertia have been saved with respect to the horizontal principal axis of the cross-section. 
The FE numerical model of the ballasted track has been created in HyperMesh and LS-PrePost software. The main dimensions of the track, the abutments and the embankment are depicted in fig. 3, whereas one of the FE mesh schemes of the track are partly reflected in fig. 7.

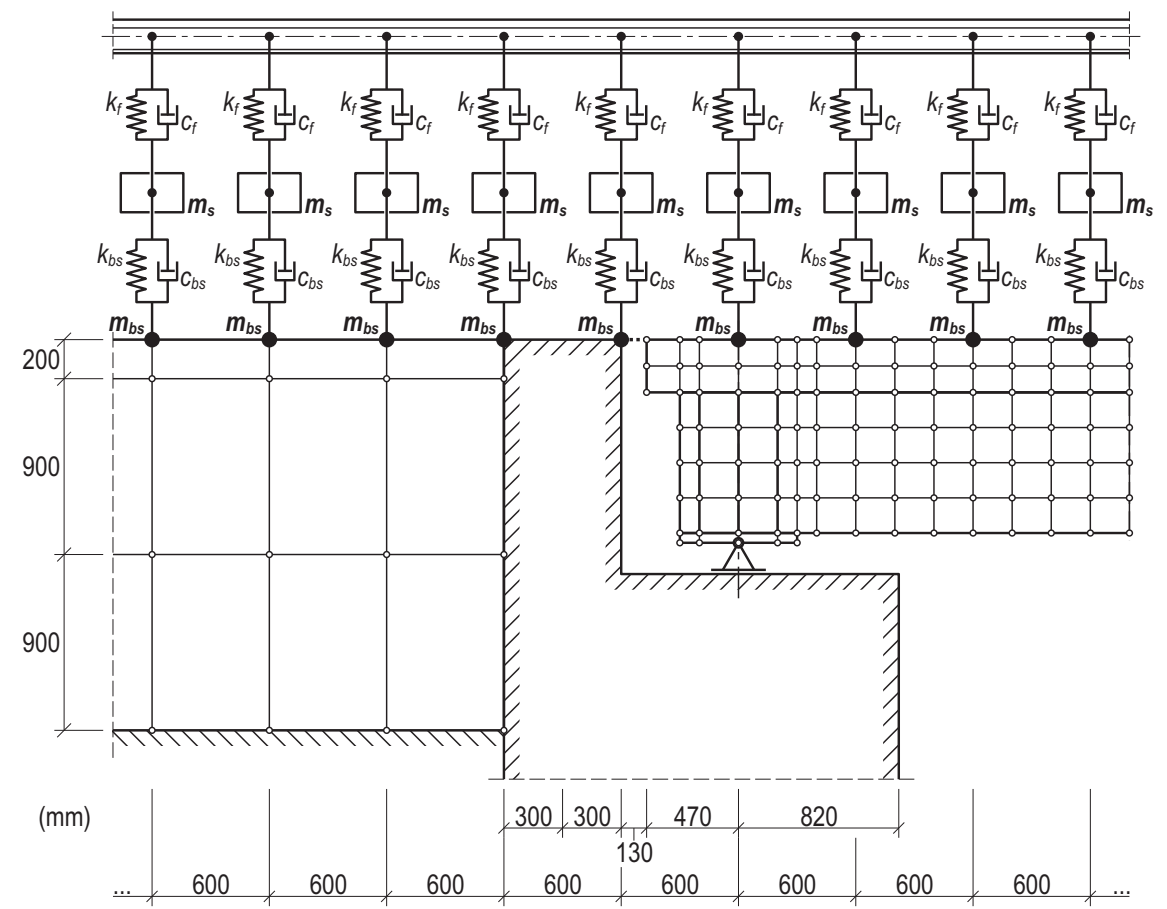

Figure 7: The side view on the physical and FE model of the track in the left abutment zone of the KNI 140070 viaduct.

The total length of the track section modelled numerically was equal to $810 \mathrm{~m}$, and contains the following sections: the initial train position (with zero static wheel pressures), the zone of increasing the static wheel pressures up to the full values, the train-track vibration stabilization zone (lasting $1 \mathrm{sec}$ ), $60 \mathrm{~m}$ long main zone (including the approach zones and the bridge), the zone of bridge free vibrations (lasting $1 \mathrm{sec}$ ), the final train position zone. In total, the FE track model contains $\sim 141,800$ beam, shell, brick and discrete elements and $\sim 21,700$ point mass elements.

Modelling of the EC 114 trainset has been performed in LS-PrePost software [15] under assumption that vibrations of the train units are symmetric with respect to the main longitudinal vertical plane of symmetry. A numerical model of the EC 114 trainset consists of the following components: carbodies, bogie frames, wheel sets, and vertical massless discrete linear viscoelastic elements reflecting the primary and secondary suspension systems. All mass components were modelled using shell and beam elements treated as rigid bodies. Wheel sets have been reflected 
by vertical rigid beam elements. Respective constraints have been put into the system via incorporating translational CONSTRAINED_JOINT_CYLINDRICAL and rotational CONSTRAINED_JOINT_REVOLUTE e-ements [15]. A side-view scheme of the 3D model of the train units is shown in fig. 8 . The values of mechanical parameters of the EC 114 train units have been determined based on Klasztorny [1] and Bachmann [14].

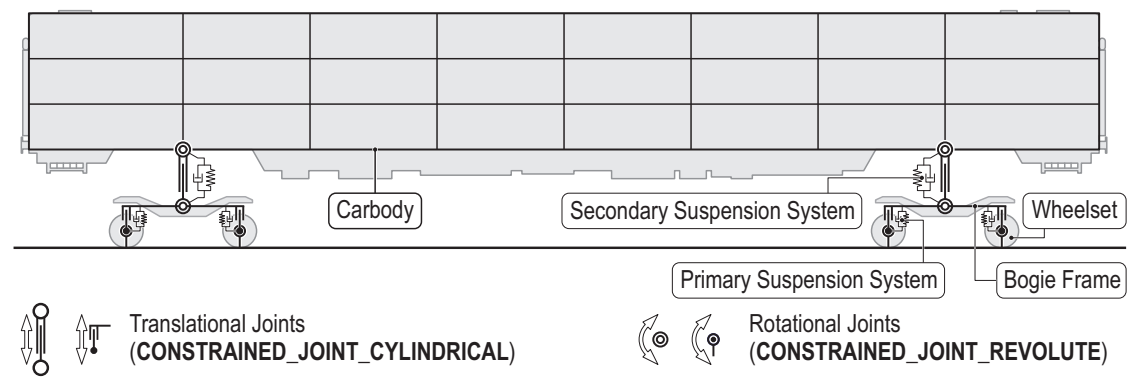

Figure 8: $\quad$ A side-view scheme of the 3D model of the EC 114 train units.

The FE models of carbodies, bogie frames and wheel sets were created at full conformity between actual vehicles and the numerical models with respect to their masses and principal mass moments of inertia. In total, the FE model of the 6-unit EC 114 train contains $\sim 950$ beam, shell and discrete finite elements and $\sim 50$ point masses. In the simulations, the DYNAMIC_RELAXATION option [15] has been replaced with loading the system by a set of vertical forces put in the moving vehicle-rail contact points according to the formula:

$$
P(t)=\frac{P_{0}}{2}\left(1-\cos \frac{\pi t}{t_{0}}\right),
$$

where $P_{0}$ is the static pressure of a single wheel on the rail head, $t_{0}=2 \mathrm{sec}$ is a time of increasing of the static pressures up to the full values $(0 \leq t \leq 2 \mathrm{sec})$.

A constant service velocity of the vehicle FE model was declared in two steps, with options INITIAL_VELOCITY for $t=0$ PRESCRIBED_MOTION_ RIGID for $t>0$ applied for all carbodies and bogies FE models [15].

Selected output quantities were registered using HISTORY_NODE_SET and HISTORY_NODE_SHELL options [15]. The sampling frequency amounts to $20 \mathrm{~Hz}$ in the zone of increasing the static wheel pressures, $200 \mathrm{~Hz}$ in the train-track vibration stabilization zone and $1,000 \mathrm{~Hz}$ in the $60 \mathrm{~m}$ long main zone. The computations have been made using the 120-P supercomputer. At the service velocity $160 \mathrm{~km} / \mathrm{h}$ the real time equals $14.4 \mathrm{sec}$, while the CPU time amounts to $\sim 90 \mathrm{hrs}$. Selected time-histories for displacements and accelerations were created using the LS-PrePost software. 


\section{A plan of the dynamic experimental test}

The KNI 140070 composite viaduct located on the Polish Central Main Line has been selected for validation tests. Spatial vibrations of the viaduct induced by EC 114 EuroCity express train moving at $160 \mathrm{~km} / \mathrm{h}$ on November 9, 2009 over the viaduct were both registered experimentally and simulated numerically.

The following types of measurements have been executed:

- measurements of selected vertical displacements vs. time using laser sensors,

- measurements of selected vertical and horizontal accelerations vs. time using accelerometers,

- measurements of the train service velocity using a high-speed camera.

Locations of the measurement points are marked in fig. 9. The vertical vibrations in displacements were measured at the midspan under webs of the main beams constituting a pair under the internal rail. KEYENCE CCD Laser Displacement Sensors of LK-G 157 type have been applied, at distance of $150 \mathrm{~mm}$ from the beam surfaces, with sampling frequency of $2000 \mathrm{~Hz}$ and measuring accuracy of $\pm 0.03 \%$. The vertical and horizontal vibrations in accelerations were measured at $1 / 4,1 / 2$, and $3 / 4$ of the bridge span under webs of selected main beams (fig. 9). The acceleration measurements were carried out with Brüel \& Kjær PULSE platform. Sampling frequency was equal to $4096 \mathrm{~Hz}$. Following types of accelerometers were used: miniature triaxial charge accelerometer 4326 A, miniature triaxial DeltaTron (CCLD) accelerometers 4504 A, high-shock DeltaTron (CCLD) accelerometers 8339-001, miniature uniaxial CCLD piezoelectric accelerometers 4507 B 005 and 751-10. PHANTOM v12 $(1280 \times 800 \mathrm{px}, 6242$ to $1 \mathrm{mln}$ fps dependent on resolution) high-speed camera has been used for measurement of the train service velocity.

$\begin{array}{llll}\text { A } & \text { |B } & \text { IC }\end{array}$

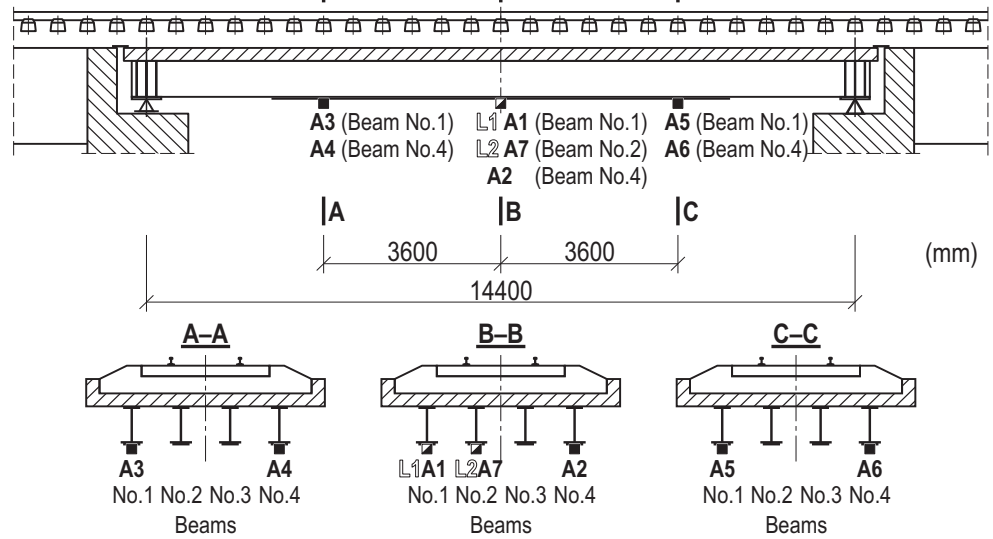

Figure 9: Dynamic experimental tests of KNI 140070 viaduct. Locations of the measurement points on the main beams: L1 and L2 - laser sensors; A1-A6 - vertical accelerometers; A7 - horizontal (lateral) accelerometer. 


\section{Results and analysis of the numerical and experimental tests}

Time-histories of the vertical deflections $w_{1}(t), w_{2}(t)$, corresponding to the main beams No. 1 and 2 are shown in fig. 10 (registered experimental time-histories) and fig. 11 (simulated time-histories). The experimental and numerical maximum deflections are set up in table 1 . These results confirm good coincidence between the simulation and the experiment. Figures 12 and 13 present the experimental and simulated acceleration time-histories of the vertical accelerator A1 (see fig. 9).

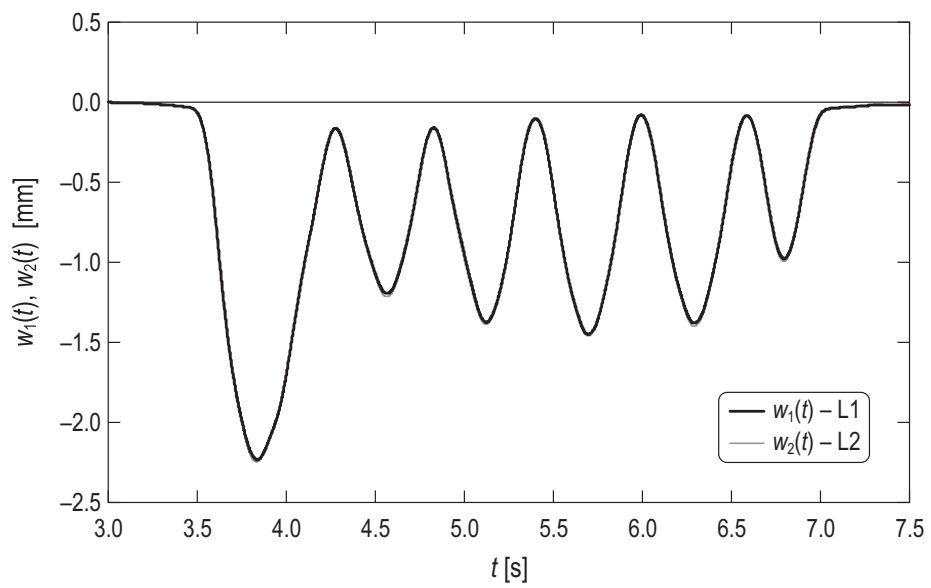

Figure 10: The validation test. Registered experimental time-histories of vertical displacements vs. time at the midspan for beams No. 1 and No. 2.

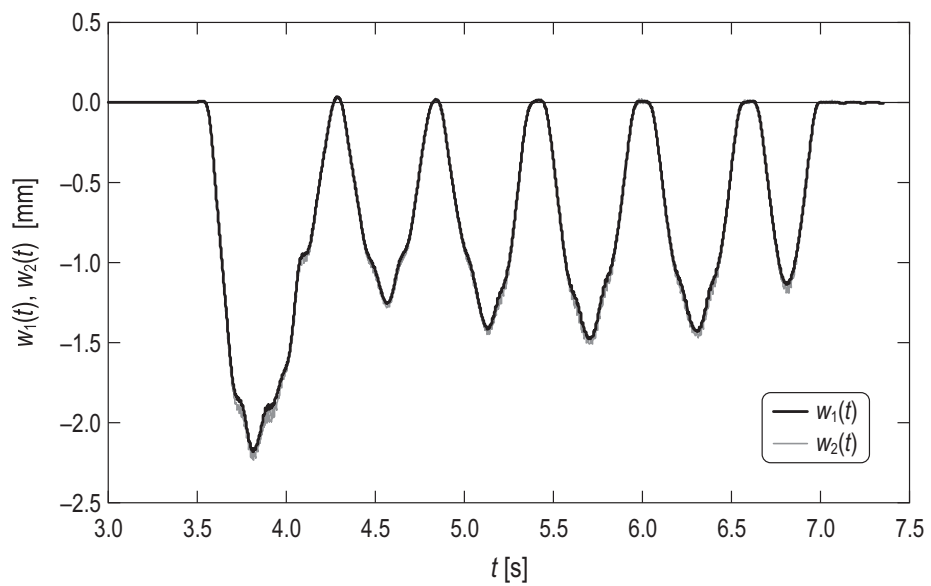

Figure 11: The validation test. Simulated time-histories of vertical displacements vs. time at the midspan for beams No. 1 and No. 2. 
Table 1: The experimental and simulated maximum vertical deflections of beams No. 1 and 2 during the validation test.

\begin{tabular}{|c|c|c|}
\hline Deflection & Experiment & FE Analysis \\
\hline $\max w_{1}(t)[\mathrm{mm}]$ & 2.23 & 2.18 \\
\hline $\max w_{2}(t)[\mathrm{mm}]$ & 2.25 & 2.23 \\
\hline
\end{tabular}



Figure 12: The experimental vertical acceleration time-history registered from accelerator A1.



Figure 13: The simulated vertical acceleration time-history corresponding to the accelerator A1.

First of all, qualitative conformity of the experimental and simulated diagrams is visible but, as expected, the experimental acceleration levels are greater than 
the numerical ones owing to neglecting the effects resulting from rolling of wheelsets.

\section{Conclusions}

Based on the results of the validation test, the following main conclusions have been formulated. The experimental validation of the numerical modelling and simulation of the BTT systems, examined on the KNI 140070 composite viaduct, located on the Polish Central Main Line, loaded by the EC 114 PRAHA express train moving at $160 \mathrm{~km} / \mathrm{h}$, is positive. The simulated (numerical) and experimental dynamic responses in displacements of the bridge superstructure are in good conformity, both qualitatively and quantitatively. Simplifications assumed in nonlinear physic modelling of the BTT systems are acceptable for one-track simply-supported bridge spans loaded by high-speed passenger trains. The simulated and experimental dynamic responses in accelerations exhibit longer durability of fully symmetric bridge superstructures compared to slightly asymmetric real superstructures. The examined modernized composite viaduct is insensitive dynamically at $160 \mathrm{~km} / \mathrm{h}$ service speed of the EC 114 train.

Note that the viaduct has been redesigned in order to adopt it to service speeds of $300-350 \mathrm{~km} / \mathrm{h}$. Further investigations should be aimed at the control and validation tests at higher service velocities of trains.

\section{Acknowledgements}

This paper is a part of a research project No. N N509 2923 35, realized by Military University of Technology, Poland in the period 2008-2011. Financial support of Ministry of Science and Higher Education, Poland is gratefully acknowledged.

\section{References}

[1] Klasztorny, M., Vibrations of single-track railway bridges under highspeed trains [in Polish], Wroclaw University of Technology Press: Wroclaw, 1987.

[2] Klasztorny, M., Dynamics of beam bridges loaded by high-speed trains [in Polish], WNT Press: Warsaw, 2005.

[3] Yang, Y.-B., et al., Vibrations of simple beams due to trains moving at high speeds, Eng. Struct., 19(11), pp. 936-944, 1997.

[4] Cheng, Y.S., et al., Vibration of railway bridges under a moving train by using bridge-track-vehicle element, Eng. Struct., 23(12), pp. 1597-1606, 2001.

[5] Au, F.T.K., et al., Impact study of cable-stayed bridge under railway traffic using various models, J. Sound \& Vibration, 240(3), pp. 447-465, 2001.

[6] Zhang, Q.-L., et al., Numerical simulation of train-bridge interaction dynamics, Computers \& Structures, 79, pp. 1059-1075, 2001. 
[7] Song, M.K., Choi, C.K., Analysis of high-speed vehicle-bridge interactions by a simplified 3-D model, Struct. Eng. \& Mech., 13(5), pp. 505-532, 2002.

[8] Modernization of the rail-line 4-E 65. Viaduct No. KNI 140070. Building Project [in Polish], Warsaw, 2007.

[9] Jones, R.M., Mechanics of composite materials, T. \& F.: London, 1999.

[10] Polish Standard: PN-H-84027-07:1984. Steel for rail-engineering. Normal rails. Sorts [in Polish], PKN Press: Warsaw, 1984.

[11] Niemierko, A., et al., Reinforcing the track and the subgrade in the approach zones to engineering objects [in Polish], Project No. M1-123, Research Institute for Roads and Bridges: Warsaw, 2009.

[12] EC114 PRAHA trainset on November 9, 2011 - Relation: Warsaw East-Praha hl. N, PKP-PLK SA Report, Warsaw, 2009.

[13] http://kolej.krb.com.pl/dt/zall.htm

[14] Bachmann, H., Vibration problems in structures, Birkhäuser: Berlin, 1995.

[15] Hallquist, J.O., LS-DYNA V971 R4 Beta. Keyword User's Manual, LSTC Co.: Livermore (CA, USA), 2009. 